\title{
Business accelerator governance
}

\section{Book Chapter}

\section{Author(s):}

Vandeweghe, Laurens; Fu, Jyun-Ying

Publication date:

2018-05-25

\section{Permanent link:}

https://doi.org/10.3929/ethz-b-000456673

Rights / license:

In Copyright - Non-Commercial Use Permitted

Originally published in:

https://doi.org/10.4337/9781786434098.00007 
CHAPTER 3: BUSINESS ACCELERATOR GOVERNANCE

\author{
Laurens Vandeweghe \\ Imperial College Business School \\ Email: 1.vandeweghe15@imperial.ac.uk
}

Jyun-Ying Fu

National Chengchi University

Email: trentfu@nccu.edu.tw 


\section{INTRODUCTION}

Extant literature on the organizational aspects of business accelerators mostly focuses on the services accelerators perform for the accelerated companies or "portfolio companies", such as training, mentorship, networking and investment activities (Miller \& Bound, 2011; Radojevich-Kelley \& Hoffmann, 2012; Caley \& Kula, 2013) and how this differs from incubators and angel investors (Cohen, 2013; Cohen \& Hochberg, 2014; Bliemel \& Flores, 2015). Further, accelerator literature has distinguished accelerator typologies based on their value proposition or the package of benefits and costs accelerators offer to start-ups (Dempwolf, Auer, \& D’Ippolito, 2015) and their "business model elements" such as program package, strategic focus, selection process, funding structure and alumni relations (Pauwels, Clarysse, Wright, \& Van Hove, 2016). While this research has been important in describing the functioning of (different models of) accelerators, it has taken a strong focus on accelerators' services as performed in relation to portfolio companies, rather than capturing all different stakeholders involved. Although some recent studies have explored the relationships between accelerators and mentors (Bernthal, 2016; Bernthal, 2017), a holistic analysis of how accelerators interact with all their internal and external stakeholders is currently missing. Given the importance of stakeholder management within accelerators (Caley \& Kula, 2013), there is need for a study that provides a more comprehensive view of accelerator governance, i.e. how accelerators build and manage relationships with internal and external stakeholders to effectively attain their organizational goals.

This chapter aims to fill this gap by identifying accelerators' main stakeholders and investigating accelerators' organizational and network governance mechanisms from a microperspective. Through a conceptual analysis, we distinguish three internal stakeholders sponsors, directors and staff - and three external stakeholders - partners, investors and portfolio companies - and reveal the organizational and network governance mechanisms at 
play in their relations with accelerators. Furthermore, we look at corporate-backed, privatebacked and public-backed accelerators and explore how these different types of accelerators govern their relationships with stakeholders. Three cases are used as examples to illustrate our notions: AppCampus, a corporate accelerator that ran between 2012 and 2015 and aimed at populating the Windows Phone platform, Techstars, a private accelerator that started in 2007 and currently runs over 28 programs worldwide, some of which have the purpose to create fast growing businesses while others are operated in partnership with corporates and have more strategic purposes, and Start-Up Chile, a public accelerator created by the Chilean Government in 2010 to position Chile as a hub of innovation in South America.

While this chapter is primarily intended for practitioners and policy makers who want to gain in-depth understanding of accelerators' stakeholders and governance mechanisms, it also contributes to the literature on accelerators and other business incubation models (Grimaldi \& Grandi, 2005). As such, we introduce a stakeholder perspective (Freeman, 1984) and the notions of organizational governance and network governance (Jones, Hesterley, \& Borgatti, 1997) into the literature on accelerators. In doing so, we contribute to the theoretical development of the accelerator concept, which several researchers have recently called for (Kohler, 2016; Mian, Lamine, \& Fayolle, 2016) and provide inspiration for the analysis of governance practices of other incubation models to which this approach may equally apply. Lastly, by looking at governance across different accelerator typologies, we respond to the call in extant literature to take the differences amongst accelerators into account (Hochberg, 2016; Pauwels et al., 2016) and contribute to further understanding of this heterogeneity.

\section{ACCELERATOR STAKEHOLDERS}

To effectively provide start-ups with time-limited, cohort-based mentoring and networking programs (Miller \& Bound, 2011; Clarysse, Wright, \& Van Hove, 2015), accelerators establish 
and manage relationships with internal and external stakeholders. A stakeholder is "any group or individual who can affect or is affected by the achievement of the organization's objectives" (Freeman, 1984: 46) and can be categorized into primary or secondary - depending on whether the stakeholder's participation is necessary or unnecessary for the survival of the focal organization (Clarkson, 1995) - and internal or external- depending on whether the stakeholder is situated within or outside of the boundaries of the focal organization (Freeman, 1984). In this chapter, we focus on the primary stakeholders (Freeman, 1984), as other accelerator literature has looked at secondary stakeholders who indirectly influence or are influenced by the accelerator, such as the local region (Fehder \& Hochberg, 2014) or the business ecosystem (Thomas, Sharapov \& Autio, 2015; Sivonen, Borella, Thomas, \& Sharapov, 2017).

Based on the extant literature (i.e. Caley \& Kula, 2013; Bernthal, 2016), six different accelerator stakeholders can be distinguished of which three internal - sponsors, directors, staff - and three external - partners, investors and portfolio companies. Sponsors fund accelerators and could be corporations, private investors such as angel investors and venture capitalists (VCs) and public or semi-public organizations such as universities and government agencies (Pauwels et al., 2016). Directors are the general managers or executive directors responsible for the strategic decision-making and the management of the day-to-day operations while accelerators' staff members (help) execute accelerators' day-to-day activities (Caley \& Kula, 2013). Partners can be conceptualized as individuals or organizations that offer services and products to accelerators or their portfolio companies for free or at a discount (Caley \& Kula, 2013). Typical partners would be mentors, professional services or technology companies, preaccelerators and other incubation models, key customer networks, etc. Investors provide the follow-on funding for accelerated ventures and could be angel investors, VCs or large corporations (Miller \& Bound, 2011). At last, portfolio companies relate to the new venture 
teams that take part in accelerator programs or ever graduated from them (Cohen \& Hochberg, 2014).

We suggest that these six stakeholder groups are typically present in any accelerator, although the importance of each stakeholder and the boundaries between external and internal stakeholders might differ amongst different accelerators. Moreover, individuals or organizations may take up more than one stakeholder role simultaneously or change roles over time. In what follows, we outline the specificities of each stakeholder group, their interplay with accelerators and the formal and informal governance mechanisms that manage the stakeholder relationships. By governance mechanisms, we refer to those mechanisms that regulate the relationships between the accelerators and the stakeholder groups. More precisely, we distinguish between organizational governance mechanisms such as equity-based incentives or explicit contracts which apply to internal stakeholders (Jensen \& Meckling,1976), and network governance mechanisms such as norms of reciprocity (Bosse and Phillips, 2014), reputation and trust to make sure that external stakeholders "engage in collective and mutually supportive action, that conflict is addressed and that network resources are acquired and utilized efficiently and effectively" (Provan \& Kenis, 2008: 231).

\section{ACCELERATOR ORGANIZATIONAL GOVERNANCE OF INTERNAL}

\section{STAKEHOLDERS}

We adopt an organizational governance perspective to look at how accelerators govern relationships with internal stakeholders such as sponsors, directors and staff to ensure that they act in accordance to accelerators' goals.

\section{Sponsors}

To finance an accelerator, one or more accelerator sponsors would set up a fund to cover the accelerator operations and - if this is included in the offer of the accelerator - an initial 
investment in the portfolio companies (Nesta, 2013). This fund would typically cover the expenses and investments of an accelerator for a period of 2 to 4 years (Deloitte, 2015). In some cases, such as for most corporate accelerators, members from the sponsor organizations also participate as accelerator mentors (Kohler, 2016). The relationships between sponsors and accelerators are governed through formal mechanisms, such as monitoring, steering and control of the accelerators' managing directors through the board of directors or investment board and formal ownership of the accelerator organization (Bernthal, 2016).

\section{Directors}

Accelerators are typically managed by hands-on operators or managing directors (Caley \& Kula, 2013; Bernthal, 2016), appointed by the sponsors and mainly responsible for codeveloping the strategy with the sponsors and executing it accordingly. The managing directors of an accelerator would typically sit on a board of directors supplemented by non-executive directors. Often, the sponsors would be involved in the board of directors or in the advisory board to follow, steer and/or control the directors on a regular basis. To a certain extent, the directors possess great autonomy in their management of the accelerator but important decisions such as venture selection would in some accelerators go through an investment board where the sponsors would be involved (Sharapov, Thomas \& Autio, 2013). Although most managing directors are governed through direct contracts, university accelerators are sometimes managed by student-volunteers (Adomdza, 2016).

\section{Staff}

Accelerators' managing directors are assisted by other staff who will be responsible for operations, marketing and external stakeholder management (Caley \& Kula, 2013). This staff would normally be governed through organization-employee relationships but may also be working voluntarily and includes entrepreneurs-in-residence (in between start-ups), technology 
experts, student interns and other staff (Bernthal, 2016). Although accelerators possess different internal structures, they are typically flat-structured, with relatively small numbers of staff focused on the executional activities that create value for the different stakeholders (Caley \& Kula, 2013; Cohen \& Hochberg, 2014).

\section{ACCELERATOR NETWORK GOVERNANCE OF EXTERNAL STAKEHOLDERS}

Within their networks, accelerators manage relationships with external stakeholders such as partners, investors and portfolio companies to attract and allocate external resources (Figure 1). In doing so, they aim to satisfy the interests of the external actors while ensuring that their differing and sometimes conflicting objectives do not manifest themselves at the expense of attaining the accelerators' goals.

\section{Figure 1: Accelerators' external stakeholders}

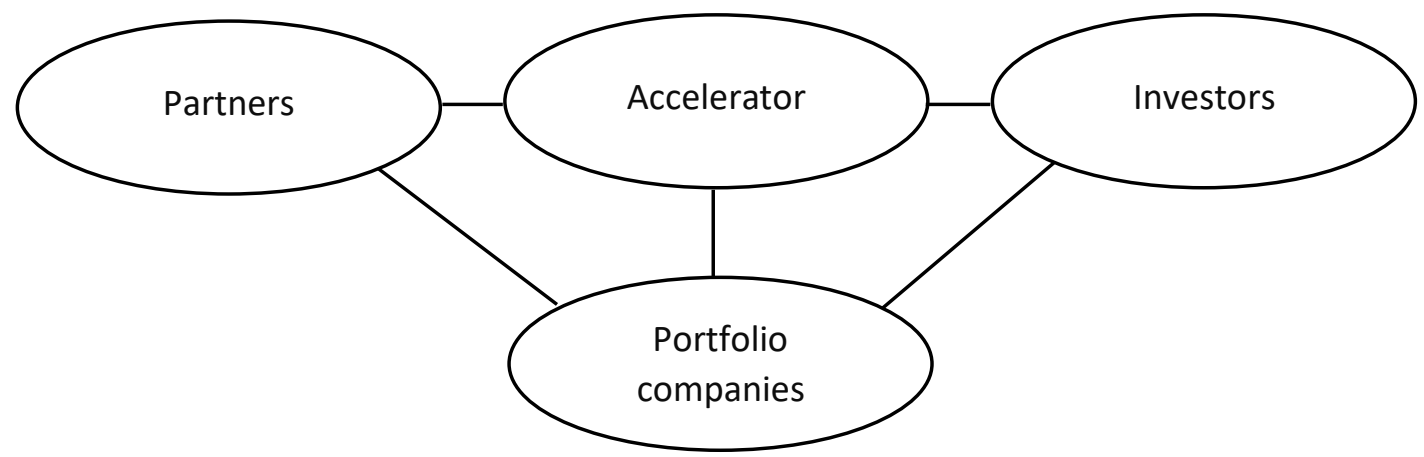

\section{Partners}

Accelerators have different kinds of partners of which the most important are mentors and service providers.

Accelerators must organize mentors - usually in the form of technology or market experts, former entrepreneurs, private investors or corporate employees (Hochberg, 2016) - to provide the strategic assistance that portfolio companies require. Rather than hire in-house experts, or contract external experts, most accelerators assemble a volunteer network of experts to mentor portfolio companies using more implicit exchanges (Bernthal, 2016). While mentorship in a 
start-up market environment would mostly be governed by a dyadic exchange of cash or equity for expert services, in an accelerator environment, mentors do typically not secure cash or equity but instead contribute voluntarily (Bernthal, 2017). Informal governance mechanisms such as trust and indirect benefits such as reputation are at play between the mentors, the portfolio companies and the accelerators. As such, mentors trust they will get a future option to invest in the portfolio company or a future job opportunity as an employee or advisor, while portfolio companies trust that mentors will not behave opportunistically by using portfolio companies' sensitive information to their personal benefits (Bernthal, 2017). Mentors also receive indirect benefits by strengthening and broadening their relationships with other mentors in the entrepreneurial community, learning from novel technology and investment trends and increasing their reputation towards parties outside the network (Bernthal, 2017). Furthermore, some mentors commit because they want to "give back" to the start-up community after a successful entrepreneurial or investor trajectory (Miller \& Bound, 2012; Nesta, 2013).

Besides mentors, accelerators also partner with professional services or technology companies. Some of them hold workshops in their area of expertise while others offer their services or products to the portfolio companies for free or at a discount (Caley \& Kula, 2013). Similarly, the relationships between professional services or technology companies and portfolio companies is based on trust as most aim to convert the portfolio companies to customers after the acceleration program. Besides inroads to new start-ups, they may also seek engagement with the accelerators' mentors and investors (Miller \& Bound, 2011). The networks of mentors and professional services or technology companies would in some accelerators be complemented with other partners such as key customer networks (Nesta, 2013) or business incubation organizations (Sharapov et al., 2013).

\section{Investors}


Accelerators play an important intermediary role between start-ups and potential investors. Specifically, accelerators aim to provide their portfolio companies with follow-on investment after the acceleration program by connecting them to more established investors such as VCs, corporate VCs and angel investors (Miller \& Bound, 2011). Accelerators build and maintain strong relationships with these follow-on investors through informal mechanisms such as investor events and the related periodic source of deal flow (Bernthal, 2016) or - for accelerators that provide funding in return for equity - formal mechanisms such as common investments. Furthermore, the reputation of the accelerator and its portfolio companies plays an essential role in gaining visibility and credibility towards investors (Plummer, Allison, \& Connelly, 2016). A good and elaborate network of investors is not only necessary for potential follow-on investment but also for offering a unique source of advice and connections to the portfolio companies (Nesta, 2013).

\section{Portfolio companies}

Most of the portfolio companies choose to be accelerated with the aim of expanding their network via mentors, gaining skills and receiving feedback on their business, benefitting from funding and co-working space (if applicable) and securing additional funding once the program is over (Christiansen, 2009; Birdsall, Jones, Lee, Somerset, \& Takaki, 2013). Both formal and informal governance mechanisms are used to govern portfolio companies. In exchange for the resources offered by the accelerator, such as financing or mentoring support, the ventures' founders often lose part of their equity to the accelerator. While this challenges the entrepreneurs' intention to retain full control of their new ventures (Wasserman, 2016), equity stakes provide a formal governance mechanism for accelerator organizations and help align the interests of accelerators with their portfolio companies. Besides equity, other formal governance mechanisms could be staged investments dependent on certain milestones or conditions (Sharapov et al., 2013; Gonzalez-Uribe \& Leatherbee, 2016) and exclusivity 
agreements to tie portfolio companies' products to a certain platform in the case of corporate accelerators (Sharapov et al., 2013). An informal governance mechanism that is often used by accelerators is "accountability" (Caley \& Kula, 2013; González-Uribe \& Leatherbee, 2016). This mechanism is executed through sessions where entrepreneurs go over the activities they had committed to execute since the last accountability session and is suggested to enhance portfolio companies' performance (González-Uribe \& Leatherbee, 2016). Other informal governance mechanisms are related to trust and social relationships nursed between company founders and directors, staff and mentors through coaching, workshops and frequent networking events during and often also after the acceleration program. The resulting social integration of the stakeholders within the network helps reduce opportunism (Bernthal, 2016).

\section{ACCELERATOR GOVERNANCE ACROSS DIFFERENT TYPES}

While accelerators have sprouted from a privately backed financial intermediary model with the sole purpose of offering deal flow to private investors, novel models have emerged from the 2010s onwards (Clarysse et al., 2015; Dempwolf et al., 2015; Pauwels et al., 2016). Accelerators now get their funding from three major sources: corporations, private investors and government schemes (Dempwolf et al., 2015). Although some accelerators receive their funding from a combination of these sources, there is often a primary institution that provides most of the funding and that will strongly impact the governance of the accelerator. Based on their sponsorship, three accelerator typologies can be distinguished: corporate accelerators, private accelerators, and public accelerators. In what follows, we present the different types of accelerators and outline the differences in their organizational and network governance.

\section{Corporate accelerators}

Corporate accelerators are funded by corporations that directly get reputational gains from the accelerators while, in the long run, aim to insource external innovation through interaction with start-ups (Hochberg, 2016; Weiblen \& Chesbrough, 2015), rejuvenate corporate culture and 
attract talent (Kohler, 2016) and contribute to the corporate's ecosystem of partners, users and customers (Dempwolf et al., 2015).

Corporate accelerators' organizational governance mechanisms depend on three organizational dimensions: their operational model, their connection to the sponsors and their leadership experience (Kanbach \& Stubner, 2016). In terms of the operational model, they could be operated by an internal team hired by the organization or outsourced to an organization that provides such services such as Techstars. Alternatively, companies could partner with others to establish a joint accelerator or join the sponsors of an existing accelerator (Hochberg, 2016). In terms of connection to the sponsors, a corporate accelerator may be run from an independent entity or from an organizational unit within the sponsor organization (Kanbach \& Stubner, 2016). The leadership experience refers to the experience of the management team, i.e. a corporate background from within the sponsor company or a background in the start-up world, which will reflect on the organizational practices (Souitaris, Zerbinati, \& Liu, 2012).

For what concerns their network governance, corporate accelerators typically offer the new ventures mentorship from a combination of internal "corporate coaches" and externals such as entrepreneurs and domain experts (Kohler, 2016). As corporate accelerators look for potential synergies between new ventures and their corporate sponsors, they may evoke a threat of misappropriation in potential accelerator applicants (Katila, Rosenberger, \& Eisenhardt, 2008). To avoid this, corporate accelerators do typically not take any equity (Clarysse et al., 2015). Examples of corporate accelerators include the Wayra Telefonica accelerators or the AppCampus ${ }^{1}$ accelerator.

\section{Private accelerators}

\footnotetext{
${ }^{1}$ For a description of AppCampus, see cases
} 
Private accelerators receive funding from private investors such as business angels and VCs with the primary aim to identify promising investment opportunities. They typically bridge the equity gap between early-stage projects and investable businesses and offer their sponsors a pipeline of investable companies, early market insights and, eventually, financial gains (Miller \& Bound, 2011). Private accelerators' directors often have extensive experience as entrepreneurs or angel investors and would adopt the organizational practices from these environments (Cohen \& Hochberg, 2014).

As their main objective is return-on-investment, private accelerators are for-profit entities and tend to favour ventures that are in later stages of development (Clarysse et al., 2015). The mentors in these accelerators are often (former) business angels or (former) entrepreneurs who volunteer in return for reputation, social and human capital and future opportunities (Bernthal, 2017). In contrast to corporate and public accelerators, private accelerators typically provide money and services in exchange for equity stakes between $5 \%$ and $10 \%$ (or an equivalent convertible note) (Miller \& Bound, 2011), which aids to align interests between the portfolio companies and their accelerators. Y Combinator and Techstars ${ }^{2}$ are the most popular examples of this type of accelerators.

\section{Public accelerators}

Public accelerators have government agencies as their main sponsors and their primary objective is often to stimulate start-up activity and foster economic growth within a specific geographic region or within a specific technological domain. They mainly receive funding from local, national and international government agencies who benefit in terms of increased start-up activity and in attracting and deploying entrepreneurial talent (Pauwels et al, 2016).

\footnotetext{
${ }^{2}$ For a description of Techstars, see cases
} 
Public accelerators' managing directors may receive quite some autonomy which risks of eroding board control and accountability (Malek, Maine, \& McCarthy, 2014).

As opposed to corporate and private accelerators, mentorship in public accelerators is typically done by (former) entrepreneurs or business developers who would provide hands-on guidance and advice on a paid basis (Pauwels et al, 2016). Hence, mentorship is governed by explicit contracts and not only by norms of reciprocity, reputation and trust. As these accelerators are non-profit organizations, they may offer stipends but do typically not request any equity in return (Pauwels et al., 2016). Start-up Chile ${ }^{3}$ or Climate KIC accelerators are examples of such type of accelerators.

\section{CASES}

We illustrate the different governance aspects of each accelerator type (corporate, private, public) by using the examples of AppCampus, Techstars and Start-Up Chile. In doing so, we will use the framework as presented in this chapter and focus on the particularities of each case.

\section{AppCampus (corporate accelerator) ${ }^{4}$}

AppCampus was an accelerator that ran from spring 2012 till spring 2015. It was funded by two corporate sponsors, Microsoft and Nokia, and hosted by Aalto Center of Entrepreneurship (ACE), a unit within Aalto University that coordinated the activities related to technology transfer and start-up activities (Farny \& Kyrö, 2015). AppCampus aimed to educate mobile application (app) developers about the Windows Phone platform and launch innovative apps on this platform. Overall, AppCampus accelerated 315 app developers and received more than

\footnotetext{
${ }^{3}$ For a description of Start-up Chile, see cases

${ }^{4}$ Source: Unless stated differently, the source for the information in this subsection comes from http://ace.aalto.fi/appcampus/ (last consulted 01/02/2017)
} 
4300 applications from over 100 countries. Its apps generated nearly seven times more downloads and twice more revenue than average in the Windows Phone Store.

AppCampus was open for everyone but highly selective, aiming for apps that were innovative, had a substantial potential and supported the key features of Nokia and Windows phones. Depending on the complexity of the app, the applicants could receive a $€ 30,000, € 50,000$ or $€ 70,000$ investment without giving up intellectual property or equity. The only requirement was that the app, once developed, would be exclusively available on the Windows Phone Store for a period of - initially six and later - three months (Thomas et al., 2015). AppCampus' teams were invited to apply for a four-week training and mentorship program organized at Aalto University. The selection process for this camp was based on the added value it could provide to the applicants. The camp offered extensive one-on-one coaching and hands-on training in mobile branding \& positioning, design, development, monetization, marketing, communications, pitching, etc. The teams also got networking opportunities with the corporate partners and potential follow-on investors (Sharapov, Thomas, \& Autio, 2014). In what follows, we look at how AppCampus applied organizational and network governance mechanisms to manage its relationships with internal and external stakeholders.

Sponsors. AppCampus' investments were covered by Nokia and Microsoft who each put 9 million EUR, while the operational expenses of the accelerator such as personnel and office space were taken on by Aalto University (Sharapov et al., 2013). AppCampus' sponsors did not only provide financial support but also offered non-financial resources to portfolio companies. As such, Nokia and Microsoft provided members of the AppCampus portfolio with access to their corporate technological, marketing and merchandising expertise (Thomas et al., 2015) while ACE was strongly embedded in the entrepreneurial community and offered inroads to the VC community in Finland as well as internationally (Farny \& Kyrö, 2015). 
Directors and staff. To ensure that the strategy met the needs of Aalto, Nokia and Microsoft, a steering board consisting of two members of staff from both Nokia and Microsoft, one member of staff from Aalto University and one independent member met monthly to evaluate AppCampus' performance and any required strategic changes (Sharapov et al., 2014). The steering board was responsible for appointing the head director and also decided upon the Key Performance Indicators which were related to the number of AppCampus apps developed and their respective success on the platform in terms of downloads, revenue and user ratings (Sharapov et al., 2014). An investment board comprised of two members of AppCampus and two members of ACE was established to select app ideas for funding (Sharapov et al., 2013).

Partners. AppCampus established partnerships to increase the magnitude and quality of the deal flow and attract expert resources to coach the teams. As for the deal flow, AppCampus established partnerships with the sponsors' accelerators and camps such as Aalto University's Startup Sauna and Startup Bootcamp, Nokia's “Invent with Nokia” and Microsoft's BizSpark. Furthermore, AppCampus established partnerships with international accelerators such as Wayra Telefonica, GameFounders, The Founder Institute and the World Bank's Infodev program. These partnerships were geared to getting more and better teams into the program. Concerning the mentors, AppCademy attracted experts both from local start-ups or investment vehicles as well as from within the sponsor companies Nokia/Microsoft/Aalto to provide mentorship and coaching on a variety of technical- and business-related subjects.

Investors. AppCampus teams were introduced to external VCs and angel investors to enable them to gain additional and/or follow-on funding. This opportunity was not only provided by the mentors but also built into the program as it organized demo-days for investors and engaged the teams to participate in pitching competitions. Also, the partnerships with other accelerators served some companies in getting follow-on funding through referral. 
Portfolio companies. AppCampus had a global remit, targeting mobile entrepreneurs around the world. By adding the requirement or exclusively launching the app on the Windows Phone platform, Nokia and Microsoft tried to capture some of the value that was created by AppCampus through increased sales of apps and mobile phones. Furthermore, to ensure app quality, the investment was staged and contingent upon successful launch of the app. As such, a team received only $30 \%$ of their grant upon acceptance of the app design while the remaining $70 \%$ was released upon launch and completion of the quality control stages (Sivonen et al., 2017).

\section{Techstars (private accelerator) ${ }^{5}$}

Techstars is a mentorship-driven private accelerator founded by one serial entrepreneur (David Cohen) and three angel investors (Brad Feld, David Brown, and Jared Polis) in Boulder, Colorado in 2006. It accepted its first-cohort of 10 companies in a three-month mentoring program in 2007. Since 2007, Techstars has expanded its accelerator activities to other cities such as Boston in 2009, Seattle in 2010, and New York City in 2010. As of early 2017, Techstars has accepted around 895 companies into its mentoring program and these ventures have raised $\$ 2.75$ billion funding, with a total of $\$ 7.5$ billion market capitalization.

Admission to Techstars is quite competitive and jointly decided by directors inside Techstars, usually with $1 \%$ acceptance rate. Once admitted, new venture teams receive a $\$ 100,000$ convertible note and $\$ 20,000$ seed funding in exchange for $6 \%$ equity stake. In addition to initial funding, Techstars provides other resources, such as access to investors, mentors, peers, etc. After a three-month mentorship program, new ventures have the opportunity to pitch to angel investors and VCs at the end of the program.

\footnotetext{
${ }^{5}$ Source: Unless stated differently, the source for the information in this subsection comes from http://www.techstars.com/ (last consulted 01/02/2017)
} 
Furthermore, Techstars actively collaborates with big corporates to outsource its accelerator model, "powered by Techstars". For example, since 2013, Techstars has collaborated with Kaplan to run an accelerator that focuses on new ventures at the nexus between education and technology and since 2014, Techstars manages the Barclay accelerator with a particular focus on fintech ${ }^{6}$. In what follows, we will focus on Techstars' private accelerators and analyse the governance mechanisms Techstars uses to manage its relationships with internal and external stakeholders.

Sponsors. The initial funding for Techstars comes from 75 different VCs. After that initial funding, Techstars also raised several additional rounds of funding. For example, in 2011, TechStars raised \$24 million new funding from several VCs and some Techstars Alumni. By raising funds from a broad range of investors, Techstars cannot only scale its model but also offer its portfolio companies access to a larger investor community.

Directors and Staff. The highest organization in Techstars is the board of directors, currently consisting of 16 people ranging from CEO to senior executives. The next organizational layer includes the managing or operating managers for each accelerator program, usually industry experts or (former) entrepreneurs. Similar to other accelerators, Techstars features a relatively flat organization with few hierarchies.

Partners. Techstars boasts a global network of over 3,000 mentors, including some renowned entrepreneurs such as Tumblr CEO David Karp and HubSpot co-founder Dharmesh Shah ${ }^{7}$. Most mentors in Techstars are business angels, serial entrepreneurs or corporate partners. In addition to direct feedback, new ventures often have access to mentors' social networks of business angels and VCs. These mentors usually volunteer for mentorship support in return for

\footnotetext{
${ }^{6}$ Source: https://www.innovationleader.com/tracking-the-corporate-supported-startup-accelerators/ (last consulted 01/02/2017)

${ }^{7}$ Source: http://www.cnbc.com/2013/11/21/whats-fueling-the-explosion-in-start-upaccelerators.html?view=story\&\%24DEVICE\%24=native-android-mobile (last consulted 01/02/2017)
} 
reputational gains from participation in Techstars and for gaining access to reputable mentors, investors or entrepreneurs. Techstars also partners up with government agencies and actively builds relationships with the government. As such, in 2011, Techstars collaborated with the White House to spur growth in entrepreneurship and is now part of the White House's Startup America Partnership initiative.

Investors. Techstars' network also features prestigious VCs and angel investors which are invited at demo days to attend the pitches or to be part of the panel. Due to Techstars' strict selection process, Techstars' boasts that it provides investors first-hand access to those innovative start-ups and early-stage firms.

Portfolio companies. Like many other private accelerators, Techstars primarily funds technology-oriented companies (web-based, software or mobile-app sectors) with national or global reach in return for a share of their equity.

\section{Start-Up Chile (public accelerator) ${ }^{8}$}

Start-Up Chile (SUP) is a business accelerator based in Santiago founded by Chilean Economic Development Agency (CORFO) in 2010. As of early 2017, CORFO has invested more than \$40 million in 1,309 SUP ventures which are estimated to be worth \$1.4 billion. Interestingly, around $76 \%$ of founders is foreign from over 70 countries, while only $24 \%$ is Chilean. The program's end goal is to attract entrepreneurial talent from all over the world and transform Chile into the hub of innovation and entrepreneurship in Latin America.

Accepted teams receive \$40,000 initial funding, a one-year working visa, and office space. The only requirement is that teams are expected to stay in Chile for around six months and actively engage in local entrepreneurial communities, such as attending workshops or lectures

\footnotetext{
${ }^{8}$ Source: Unless stated differently, the source for the information in this subsection comes from http://www.startupchile.org/ (last consulted 01/02/2017)
} 
held by local entrepreneurs. Different from other accelerators such as Techstars, SUP provides seed funding but does not take any equity.

SUP's successful model has been replicated by a number of countries around the world. For example, Start-Up Brasil, Start-Up Perú, and Malaysia's MaGIC have imitated the SUP model with the aim of boosting local economy by promoting local entrepreneurial ecosystems ${ }^{9}$. In what follows, we identify the different internal and external stakeholders of SUP and the governance mechanisms at play in their relation with SUP.

Sponsors. SUP is under the supervision CORFO, Chile's development agency. The annual operating cost for SUP is around $\$ 15$ million and is all supported by the Chilean government.

Directors and Staff. The advisory board is the highest organization in SUP and consists of a group of professionals that provides advice or develops practices for SUP (González-Uribe \& Leatherbee, 2016). The board holds several meetings during the year and makes suggestions for changes to the implementation of the SUP program. The executive team is led by an executive director, accompanied by an accelerator program director, an operations director, a marketing and communications director and a community and network director.

Partners. SUP features a program that helps foreign entrepreneurs to connect with local (aspiring) entrepreneurs (Melo, 2012). For example, SUP initiates the "internship" program that targets local undergraduate students, primarily from Santiago's universities. Once accepted, those undergraduate students are working with SUP staff teams or SUP venture teams. SUP also sets up a website that helps SUPs' venture teams to search for internships, hence stimulating the knowledge flow between the local community and the talented start-ups. Furthermore, SUP established the Godfathers ("Padrinos") program that assigns a local buddy

\footnotetext{
${ }^{9}$ Source: https://techcrunch.com/2016/10/16/a-look-into-chiles-innovative-startup-government/ (last consulted 01/02/2017)
} 
(usually local entrepreneur) who helps acclimatize foreign SUP entrepreneurs to the new environment (Carmel \& Richman, 2013). SUP matches the background of accepted foreign entrepreneurs with someone from the local business community, primarily based on language and interests. The matched local buddy would then help these participants with their daily basic needs, such as finding their flats, opening a bank account, getting a local mobile number or applying for their IDs. By providing those participants with such 'soft landing' assistance, SUP creates links between the local business community and the foreign participants.

Investors. By leveraging the reputation of CORFO, venture teams at SUP have the opportunity to pitch in front of many prestigious national and foreign investors during the demo day or final pitching event upon graduation.

Portfolio companies. SUP typically accepts two cohorts of new ventures per year, with around 80 to 100 ventures per batch. SUP does not accept professional service firms such as consulting firms or export/import companies as these firms are not easily scalable. As SUP seeks to foster the entrepreneurial culture in Chile, their network governance primarily focuses on how to connect its local community and Chilean entrepreneurs more broadly with global talented entrepreneurs. Different from other accelerators, SUP does not aim to benefit from acquisitions or IPOs. Instead, SUP views their portfolio companies as conduits that bring in entrepreneurial or innovation spirits from around the world (Carmel \& Richman, 2013).

\section{CONCLUSION}

This study extends previous accelerator research by providing a holistic view on the microaspects of accelerator governance, encompassing its relationships with internal and external stakeholders and applying the resulting framework to the different types of accelerators. It contributes to practice and theory in the following ways.

\section{Managerial and policy implications}


While stakeholder management is an important activity within accelerators (Caley \& Kula, 2013), a holistic framework for identifying, analyzing and managing stakeholder relationships has been largely missing. This chapter advances such framework and suggests that it can be a useful tool for policy makers and practitioners to gain in-depth understanding of accelerators' governance mechanisms. It also complements the existing literature on how to design an accelerator (Deloitte, 2015; Christiansen, 2009; Kohler, 2016; Sivonen et al., 2017) and can be of additional value to practitioners and policy makers that intend to found accelerators. Moreover, although the framework has been derived from extensive analysis of the accelerator literature, it could also serve the analysis of governance practices of related business incubation models such as pre-accelerators and third generation incubators (Bruneel, Ratinho, Clarysse, \& Groen, 2012).

\section{Theoretical implications}

So far, few has been known about accelerators' important internal and external stakeholders and their relationships with the accelerator. While some studies looked at the relationship between accelerators and one of their stakeholders (Bernthal, 2016; Bernthal, 2017), a holistic analysis of accelerators' stakeholders was largely missing. This chapter provides such analysis and sheds light on the governance mechanisms at play between accelerators and their main internal stakeholders - sponsors, directors and staff - and external stakeholders - partners, investors and portfolio companies. Second, we respond to the call in extant literature to take the heterogeneity amongst accelerators into account by looking into the differences in governance mechanisms across different accelerator sponsorship structures - corporate, private and public - and applying our framework to three different cases: (1) AppCampus, primarily sponsored by Microsoft and Nokia, (2) Techstars, sponsored by VCs and angel investors and (3) Start-Up Chile, sponsored by the Chilean agency for economic development. Third, by introducing the stakeholder perspective (Freeman, 1984) and the notions of organizational and 
network governance (Jones et al., 1997) into the literature on accelerators, we respond to the call of accelerator researchers to further theoretical development of the accelerator concept (Kohler, 2016; Mian, Lamine \& Fayolle, 2016) and provide inspiration for theorizing other business incubation models.

\section{Limitations and future research}

While this conceptual study of accelerator governance provided an in-depth holistic analysis of how accelerators manage stakeholder relationships, it did not specifically focus on stakeholders' conflicting interests. Nevertheless, this may be an important direction for future research as stakeholders' differing objectives, if any, may lead to interest conflicts and even harm an accelerator. Although some research has looked at how the problem of interest misalignment between accelerators and mentors could be alleviated (Bernthal, 2016; Bernthal, 2017), future research should explore how accelerators resolve conflicting interests from different stakeholder groups. Moreover, conflicting objectives may not only come from stakeholders' different interests but also from their different origins or institutional contexts. Accelerators operate in complex institutional environments and often have to manage demands from stakeholders coming from different institutional contexts, such as corporate sponsors and directors with VC experience in the case of many corporate accelerators (Souitaris et al., 2012). These different stakeholders hold different norms and practices and exert influence over accelerators to adopt these. The so-called institutional forces may not only be diverse but often also competing. Hence, dealing with these competing institutional forces is a challenging task that has been largely overlooked by scholars and practitioners. More research is needed on how accelerators can resolve competing institutional forces while establishing or maintaining their legitimacy or the perception that their actions are desirable within each of these systems of norms (Suchman, 1995). 
Besides the reconciliation of interest conflicts, we suggest that another interesting avenue for future research on accelerator governance relates to the differences across accelerators and their impact on portfolio companies' trajectories. As Gonzalez-Uribe and Leatherbee (2016) suggested that governance mechanisms such as "accountability" are likely to influence portfolio companies' probability of raising seed and venture-capital funding, future research should delve deeper into the differences in governance across accelerators and their impact on portfolio companies' performance. This could be of importance to accelerators and other incubation models with comparable set-ups.

\section{REFERENCES}

Adomdza, G. K. (2016). Choosing Between a Student-Run and Professionally Managed Venture Accelerator. Entrepreneurship Theory and Practice, 40(4), 943-956.

Bernthal, B. (2016). Investment Accelerators. Stanford Journal of Law, Business, \& Finance. 21(2), 139-191.

Bernthal, B., (2017) Who Needs Contracts? Generalized Exchange within Investment Accelerators, 100 Marquette Law Review, Forthcoming: 2017.

Birdsall, M., Jones, C., Lee, C., Somerset, C., \& Takaki, S. (2013). Business accelerators: The evolution of a rapidly growing industry. University of Cambridge, Cambridge (MBA Dissertation at Judge Business School and Jesus College).

Bliemel, M., \& Flores, R. G. (2015, January). Defining and Differentiating Accelerators: Insights From The Australian Context. In Academy of Management Proceedings (Vol. 2015, No. 1, p. 14151). Academy of Management.

Bosse, D., \& Phillips, R. (2016). Agency Theory and Bounded Self-Interest. Academy of Management Review. 41(2), 276-297.

Bruneel, J., Ratinho, T., Clarysse, B., \& Groen, A. (2012). The Evolution of Business Incubators: Comparing demand and supply of business incubation services across different incubator generations. Technovation, 32(2), 110-121.

Caley, E., \& Kula, H. (2013). Seeding success: Canada's startup accelerators. MaRS, Toronto, Canada.

Carmel, Erran, and Jessica Richman. (2013). Building International Social Capital at the Startup Chile Accelerator. Working paper available at SSRN:

https://papers.ssrn.com/sol3/papers.cfm?abstract $\mathrm{id}=2326003$ (last consulted 01/02/2017)

Christiansen, J., 2009. Copying Y Combinator, a framework for developing seed accelerator programmes. University of Cambridge, Cambridge (MBA Dissertation at Judge Business School and Jesus College).

Clarysse, B., Wright, M., \& Van Hove, J. (2015). A look inside accelerators. London: Nesta.

Clarkson, M. E. (1995). A stakeholder framework for analyzing and evaluating corporate social performance. Academy of management review, 20(1), 92-117.

Cohen, S. (2013). What do accelerators do? Insights from incubators and angels. innovations, 8(3-4), $19-25$

Cohen, S., \& Hochberg, Y. V. (2014). Accelerating startups: The seed accelerator phenomenon. Available at SSRN: https://papers.ssrn.com/sol3/papers.cfm?abstract $\mathrm{id}=2418000$ (last consulted 01/02/2017) 
Deloitte (2015). Design Principles for Building a Succesfull Corporate Accelerator. Available at: https://www2.deloitte.com/content/dam/Deloitte/de/Documents/technology/CorporateAccelerator-EN.pdf (last consulted 01/02/2017)

Dempwolf, C. S., Auer, J., \& D'Ippolito, M. (2014). Innovation Accelerators: Defining Characteristics Among Startup Assistance Organizations. The US Small Business Administration. (last consulted 01/02/2017)

Farny, S., \& Kyrö, P. (2015). Entrepreneurial Aalto: where science and art meet technology and business. In: Foss, L. and Gibson, D. (eds.), The Entrepreneurial University: Context and Institutional Change, 150-166. New York: Routledge.

Fehder, D. C., \& Hochberg, Y. V. (2014). Accelerators and the regional supply of venture capital investment. Available at SSRN. (last consulted 01/02/2017)

Freeman, R. E. (1984). Strategic management: A stakeholder approach. Boston: Pitman

González-Uribe, J., \& Leatherbee, M. (2016). The Effects of Business Accelerators on Venture Performance: Evidence from Start-Up Chile. Working paper available at SSRN: https://papers.ssrn.com/sol3/papers.cfm?abstract_id=2651158 (last consulted 01/02/2017)

Grimaldi, R., \& Grandi, A. (2005). Business incubators and new venture creation: an assessment of incubating models. Technovation, 25(2), 111-121.

Hochberg, Y. V. (2016). Accelerating Entrepreneurs and Ecosystems: The Seed Accelerator Model. Innovation Policy and the Economy, 16(1), 25-51.

Jensen, M. C., \& Meckling, W. H. (1976). Theory of the firm: Managerial behavior, agency costs and ownership structure. Journal of financial economics, 3(4), 305-360.

Jones, C., Hesterly, W. S., \& Borgatti, S. P. (1997). A general theory of network governance: Exchange conditions and social mechanisms. Academy of management review, 22(4), 911-945.

Katila, R., Rosenberger, J. D., \& Eisenhardt, K. M. (2008). Swimming with sharks: Technology ventures, defense mechanisms and corporate relationships. Administrative Science Quarterly, 53(2), 295-332.

Kanbach, D. K., \& Stubner, S. (2016). Corporate Accelerators As Recent Form Of Startup Engagement: The What, The Why, And The How. Journal of Applied Business Research (JABR), 32(6), 1761-1776.

Kohler, T. (2016). Corporate accelerators: Building bridges between corporations and startups. Business Horizons, 59(3), 347-357.

Malek, K., Maine, E., \& McCarthy, I. P. (2014). A typology of clean technology commercialization accelerators. Journal of Engineering and Technology Management, 32, 26-39.

Melo, H. (2012). Prosperity through Connectedness (Innovations Case Narrative: Start-Up Chile). innovations, 7(2), 19-23.

Mian, S., Lamine, W., \& Fayolle, A. (2016). Technology business incubation: An overview of the state of knowledge. Technovation, 50, 1-12.

Miller, P., \& Bound, K. (2011). The Startup Factories: The rise of accelerator programmes to support new technology ventures. Nesta. (last consulted 01/02/2017)

Nesta (2014). Startup Accelerator Programmes: A Practice Guide. Available at: http://www.nesta.org.uk/publications/startup-accelerator-programmes-practice-guide (last consulted 01/02/2017)

Pauwels, C., Clarysse, B., Wright, M., \& Van Hove, J. (2016). Understanding a new generation incubation model: The accelerator. Technovation, 50, 13-24.

Plummer, L. A., Allison, T. H., \& Connelly, B. L. (2016). Better together? Signaling interactions in new venture pursuit of initial external capital. Academy of Management Journal, 59(5), 15851604.

Provan, K. G., \& Kenis, P. (2008). Modes of network governance: Structure, management, and effectiveness. Journal of public administration research and theory, 18(2), 229-252.

Radojevich-Kelley, N., \& Hoffman, D. L. (2012). Analysis of accelerator companies: An exploratory case study of their programs, processes, and early results. Small Business Institute ${ }^{\circledR}$ Journal, $8(2), 54-70$.

Sharapov, D., Thomas, L. D., \& Autio, E. (2013). Building ecosystem momentum: The case of AppCampus. In 35th DRUID Celebration Conference. 
Sharapov, D., Thomas, L.D.W., and Autio, E. (2014). AppCampus. In Healy, A., Perkmann, M., Goddard, J., and Kempton, L. (eds.): Measuring the impact of university business cooperation (EAC/23/2012): Case Studies: 4-16. Luxembourg: Publications Office of the European Union.

Sivonen, P., Borella, P., Thomas, L., \& Sharapov, D. (2015). How an Accelerator can Catalyse your Ecosystem. European Business Review.

Souitaris, V., Zerbinati, S., \& Liu, G. (2012). Which iron cage? Endo-and exoisomorphism in corporate venture capital programs. Academy of Management Journal, 55(2), 477-505.

Suchman, M. C. (1995). Managing legitimacy: Strategic and institutional approaches. Academy of management review, 20(3), 571-610.

Thomas, L. D., Sharapov, D., \& Autio, E. (2018). Linking entrepreneurial and innovation ecosystems: The case of AppCampus. In: Alvarez, S., Carayannis, E. G., Dagnino, G. \& Faraci, R. (eds.), Entrepreneurial Ecosystems and the Diffusion of Startups. Cheltenham, UK and Northampton, MA, USA: Edward Elgar Publishing, forthcoming.Wasserman, N. (2016). The throne vs. the kingdom: Founder control and value creation in startups. Strategic Management Journal.

Weiblen, T., \& Chesbrough, H. W. (2015). Engaging with startups to enhance corporate innovation. California Management Review, 57(2), 66-90. 